\title{
Peña Ardid, Carmen (ed.), Historia cultural de la Transición. Pensamiento crítico y ficciones en literatura, cine y televisión. Madrid: Los Libros de la Catarata, 2019, 270 págs.
}

En el siglo XXI, la disputa por el sentido de la transición española ha traspasado el ámbito sociopolítico y se ha instalado con firmeza en el académico. Uno de los aspectos que más atención ha suscitado en los últimos lustros han sido los relatos a través de los que los distintos autores han tratado de fijar dicho sentido a lo largo del periodo histórico inaugurado por el mencionado proceso político. Los ejercicios de relectura de la Transición a partir de sus representaciones narrativas han adquirido unos tintes cada vez más críticos, motivados por la constatación más o menos generalizada de los límites del cambio democrático.

La obra colectiva Historia cultural de la Transición. Pensamiento crítico y ficciones en literatura, cine y televisión, coordinada por la profesora de la Universidad de Zaragoza Carmen Peña Ardid, se inscribe, precisamente, en esta corriente crítica, puesto que, a pesar de su heterogeneidad, prácticamente la totalidad de los catorce trabajos reunidos en este volumen coinciden en abordar el estudio de un conjunto de representaciones culturales que, bien coetáneas a la coyuntura de la reforma política y, sobre todo, producidas posteriormente, vienen "a cuestionar no solo el relato oficial de lo que fue el tránsito a la democracia - la imagen de un cambio pacífico, dirigido por las elites y amparado en una reconciliación de los españoles para afrontar un nuevo futuro-, sino también el alcance del proceso democratizador en sí mismo".

El libro parte de la concepción de que, como señala Peña Ardid en su preámbulo, la esfera cultural constituye una parte importante del análisis histórico dado "el papel que tienen los objetos artísticos, intelectuales y culturales en la forma en la que se articula la experiencia y la memoria colectiva del pasado". Esta perspectiva explica que en sus páginas convivan investigaciones sobre narrativas periodísticas, literarias, teatrales, cinematográficas o televisivas que, a pesar de diferir en sus retóricas representativas y en sus modos de interpelar al público, permiten entender, gracias a su disposición diacrónica, cómo las mediaciones culturales sobre el pasado suelen activarse en función de posiciones personales o institucionales presentes y de perspectivas futuras.

Si bien las representaciones ficcionales son las que, a tenor del título, centran el grueso del volumen, este se abre con dos capítulos cuyas narrativas descansan sobre sendos géneros de no-ficción, las memorias y los artículos periodísticos de opinión. En el primero, que lleva por título "La urgencia de dejar atrás un pasado incómodo: algunos ejemplos de reacomodaciones y silencios durante la transición política", José Luis Calvo Carilla analiza las memorias que destacados intelectuales del régimen franquista como José Luis López Aranguren, Pedro Laín Entralgo o Dionisio Ridruejo publicaron estratégicamente ante el advenimiento de la Transición para compartir sus "transiciones ideológicas personales". Según este autor, por lo general, en dichas obras "el deseo de autojustificación personal se impuso sobre una voluntad confesional estricta", al igual que en las novelas de inspiración confesional de reconocidos literatos como José Luis Sampedro y Gonzalo Torrente Ballester, cuya vaguedad autobiográfica, en el primer caso, y sus oportunistas silencios, en el segundo, explora Calvo Carilla en la segunda parte de su ensayo. 
La palabra constituye también el objeto de estudio central del segundo capítulo, firmado por Carlos Femenías Ferrá, y titulado "Gramática intelectual en la Transición. Rafael Sánchez Ferlosio y Agustín García Calvo en El País”. Sin embargo, en este caso, el lenguaje no tiene como fin enmascarar la realidad, sino evidenciarla, y los autores de los textos analizados, los citados Sánchez Ferlosio y García Calvo, no son falangistas conversos sino declarados representantes de la disidencia antifranquista que, tras la muerte del dictador, encuentran en las páginas de El País —el periódico de referencia de la Transición-, el altavoz idóneo para hacer oír su discurso crítico ante las pretensiones del nuevo Estado de colonizar verbalmente la esfera pública. Sus tribunas periodísticas denuncian, en opinión de Feremías, la imposición de "un marco discursivo hegemónico" que, a los ojos del Sánchez Ferlosio, trata "de mediatizar y prefigurar los términos por donde debía discurrir el razonamiento" de los ciudadanos, y a los de García Calvo, de "expulsar el conflicto" entre estos y el Estado.

En el tercer capítulo arranca propiamente el estudio de las ficciones que rememoran la etapa transicional. Tanto este como el cuarto y el quinto acometen el examen de su representación literaria. El estudio panorámico que ofrecen en conjunto los trabajos de Juan Carlos Ara Torralba, María Ángeles Naval y Gonzalo Pasamar permite apreciar la evolución del recuerdo de la Transición propuesto por el género novelístico desde finales de los años setenta hasta la actualidad. En este sentido, las interpretaciones elusivas y/o mitificadoras del tránsito a la democracia que, gestadas a través de "la mostración de traumas íntimos, larvados en el ámbito privado", recorren, según Ara Torralba, las obras de muchos autores durante los años fundacionales de la percepción del periodo (1983-1992), dejan paso en los primeros 2000 a relatos más comprometidos. Estos no solo evitan el "alto grado de autocomplacencia con la nueva modernidad española" advertido - salvo en contadas excepciones, como Pájaro en una tormenta (1984) de Isaac Montero- en las novelas del pretérito inmediato, sino que, como afirma María Ángeles Naval, enarbolan abiertamente "la denuncia de la represión, la censura y la ilegitimidad del régimen franquista surgido del golpe de Estado y de la guerra posterior" y, a partir de 2011, propugnan, además, "la revisión de las políticas de reconciliación y consenso, y de paso de todo el proceso político democrático inaugurado por la Transición", convirtiendo de ese modo a la novela en un agente social más del debate político del momento.

Caso aparte lo constituye la reconstrucción memorística de la Transición realizada por la novela negra, un género que, para Gonzalo Pasamar, alcanza su madurez literaria en España en aquellos años, de la mano, entre otros, de Manuel Vázquez Montalbán. La actitud elusiva del septenio transicional que Ara Torralba atribuye a muchos de los representantes de la "nueva narrativa hispánica" en la década de los ochenta no es compartida en absoluto por los cultivadores del thriller, que en una primera etapa —que Pasamar sitúa entre 1977 y 1986 - recrean el ambiente político y social que rodeó al proceso democratizador, aludiendo sin ambages a episodios y personajes conocidos, para conectar al lector con "algunas emociones y sentimientos contemporáneos: incertidumbre, expectativa, temor, sensación extrema de dificultad y desencanto". En la segunda etapa, que se extendería desde finales de los noventa hasta hoy, la evocación coetánea de aquellos años ha sido reemplazada por otro tipo de representaciones que, moldeadas por las nuevas claves políticas y culturales, discurren entre la nostalgia y el negacionismo del propio acontecimiento. 
Igualmente sugestivos resultan los dos capítulos siguientes, el sexto y el séptimo, en los que Teresa García-Abad e Isabel Carabantes analizan la contribución — pocas veces reconocida - del teatro a la configuración de la memoria colectiva de la Transición desde sus postrimerías. En "Representaciones de 'la Cosa' o el monstruo reprimido: transición y teatro", García-Abad contrapone las estrategias dramáticas que en la naciente democracia utilizan para aludir al nuevo marco de convivencia común quienes ven cómo se desbarata "la ilusión de un proyecto utópico de recuperación del pensamiento de izquierdas" y aquellos que "se aferran a un orden definitivamente clausurado". La autora concluye que, mientras los primeros soslayan, como muchos novelistas del momento, la representación "frontal" del tiempo presente refugiándose en "alegorías, analepsis históricas, símbolos, mitos y metáforas", para asegurar quizá la consecución de la democracia en España, los segundos se valen de la sátira para expresar abiertamente su descontento con las reformas auspiciadas por el aperturismo.

Por su parte, en "La Cultura de la Transición evita el drama, pero el drama se vuelca con la Cultura de la Transición", Isabel Carabantes, partiendo de la crítica del libro-manifiesto CT o la Cultura de la Transición. Crítica a 35 años de cultura española (2012), de manera particular, por obviar en sus páginas al teatro como género y como industria, pero, sobre todo, como manifestación cultural, reivindica el papel de la escena en la reinterpretación del citado periodo histórico, a través del estudio de una veintena de obras producidas por dramaturgos españoles a partir de mediados de los noventa. Carabantes las clasifica en tres grandes grupos: las que tienen como protagonistas a personajes anónimos, quienes recuerdan desde una óptica personal las vivencias de aquellos años; las que pueden enmarcarse dentro del llamado teatro documento, porque versan sobre personas reales y recrean varios de sus discursos y episodios clave, como la legalización del PCE o la muerte de Franco, y, por último, las que han revisitado algunos de esos acontecimientos pero en clave humorística.

Los restantes capítulos que componen la segunda parte de Historia cultural de la Transición están dedicados a rastrear la transición española en el cine y, sobre todo, en la televisión. Los dos ensayos fílmicos, que ocupan los capítulos octavo y noveno, tienen como autores, respectivamente, a Víctor Mora Gaspar y Christelle Colin. En "Política y sexo en transición. La construcción de la normatividad sexual desde las nuevas narrativas cinematográficas", el primero se cuestiona hasta qué punto el cambio político tuvo su reflejo en la modificación de la representación de las sexualidades consideradas popularmente como "marginales" en las películas producidas a partir de la década de 1970, para concluir que, a pesar de que estas "supusieron desde luego una apertura en el imaginario colectivo para nuevas realidades [...], sostuvieron, por otro lado, un carácter esencialmente continuista para cuestiones como el binarismo y la jerarquía en el sistema sexo-genérico".

Colin, en cambio, propone un estudio monográfico de un único filme: La isla mínima (2014), de Alberto Rodríguez. Junto a las consideraciones sobre la experimentación estética del citado director con el género negro, el autor subraya el distanciamiento exhibido por la cinta respecto de la visión mitificadora del proceso democratizador predominante en algunos relatos televisivos coetáneos como 23-F. La película (2011), mediante la plasmación de "las contradicciones de un proceso transicional que surgen [...] de la persistencia del pasado franquista en el presente de los años ochenta". No obstante, en su opinión, no cabe situar a La isla mínima entre los discursos más críticos con el mito de la Transición, porque, en sus últimas escenas, 
reactiva "la idea clave del consenso [...], fundamental en la elaboración de dicho mito" al mostrar, al menos aparentemente, la superación de los antagonismos entre los policías protagonistas.

El contenido del capítulo de Manuel Palacio, el décimo de la obra, si bien no resulta especialmente novedoso, sirve para enmarcar las reflexiones televisivas que cierran el volumen, ya que, desde su concepción de la televisión como "constructora de símbolos culturales para el espacio público", el autor revisa otra vez el papel que jugó la pequeña pantalla en la democratización y modernización del país, y esboza los dos discursos dominantes que sobre la Transición "conviven y combaten" hoy en ella a través de un estudio comparativo de cinco series - una de producción nacional y las otras cuatro autonómicas, que excepcionalmente, presentan una naturaleza documental antes que ficcional - que la han abordado desde finales del siglo XX. El primero, que impregnaría la canónica serie de Victoria Prego y Elías Andrés La Transición (1995), "subraya lo que tiene de reconciliación entre unos españoles que juntos superan el pasado y construyen el futuro", mientras que el segundo, presente en la mayoría de las "contranarrativas" regionales posteriores considera, en palabras de Palacio, que aquella fue un "proceso controlado y vigilado por fuerzas de raigambres en el franquismo" que "instauró el olvido y la amnesia del pasado dictatorial" y estableció "para su desarrollo unas líneas rojas infranqueables tales como la forma monárquica del Estado, las bases del poder político y financiero o el régimen territorial español".

Entre estos discursos se sitúan, en efecto, las demás producciones televisivas analizadas. Dentro de las narrativas críticas, se encuentran, por ejemplo, las adaptaciones literarias de las obras de los ya citados Manuel Vázquez Montalbán e Isaac Montero, Pepe Carvalho (1986) y Pájaro en una tormenta (1990), o la adaptación televisiva de las obras transicionales más emblemáticas de la compañía catalana de teatro colectivo Dagoll Dagom, abordadas en los capítulos undécimo y duodécimo, respectivamente. En las primeras profundiza Luis Miguel Fernández, quien considera no solo los aspectos creativos y de contenido de ambas realizaciones, sino también "las coordenadas en las que fueron concebidas por sus autores y utilizadas por los responsables de TVE", con el fin de dar razón de la fisura que su descarnada crónica social de aquellos años abrió en la entonces preeminente imagen de la Transición como proceso ejemplar, consensuado y providencialista. De las segundas se ocupa David R. George Jr., quien, además de reparar en la recuperación de un "espacio público democrático" que supuso la transferencia del escenario a la pequeña pantalla de obras que, como Nocturn per a acordió (1975) o Antaviana (1978), reivindicaban a autores catalanes censurados durante el franquismo como Joan Salvat Papasseit o Pere Calders - una revitalización que, a su parecer, implicó también, sobre todo por parte de la autonómica TV3, "activar un dispositivo contestatario [...] de la identidad catalana"subraya la crítica que Dagoll Dagom vertió a través de ellas respecto a la "cristalización democrática en el reciclaje de formas y actitudes colectivas" que poco tenían que ver con la idealización previa del cambio político.

En las antípodas de los discursos revisionistas cabe emplazar, por el contrario, al episodio "Cualquier tiempo pasado" de la serie de Televisión Española El Ministerio del Tiempo, sobre el que Elena Cueto Asín vuele la mirada en el decimotercer capítulo titulado "Guernica como patrimonio y victoria institucional. El Ministerio del Tiempo". En él los agentes protagonistas tienen como misión velar por que no se frustre el traslado a Madrid en 1981 del Guernica de Pablo Picasso, dado que constituye, en los 
estertores de la Transición, un hito en la "reconciliación de las dos Españas tras la dictadura". En este sentido, dicho episodio supone una continuidad en 2015 de la conmemoración mediática de la adquisición del lienzo por parte del gobierno español que la prensa y la televisión llevaron a cabo a principios de los ochenta y, sobre todo, "contribuye a ubicar la Transición como un periodo más del pasado superado, cerrado como tal a indagaciones que cuestionen su estabilidad de relato hegemónico".

Por fin, "Leyendo entre líneas: la ficción televisiva de Pilar Miró, Josefina Molina y Lola Salvador durante la Transición", el capítulo con el que concluye Historia cultural de la Transición, introduce la perspectiva de género - un campo de los estudios culturales particularmente fructífero en los últimos años-en su investigación sobre la televisión de la Transición. En él Natalia Martínez Pérez indaga en las adaptaciones literarias de grandes clásicos y modernos que las mencionadas guionistas y realizadoras concibieron entre 1974 y 1981 para su emisión en espacios dramáticos de TVE como Novela, Estudio 1 o Los libros. Si bien, desde su punto de vista, "la perspectiva de estas creadoras fue sobre todo conciliadora al mostrar que, mediante la tolerancia y el diálogo, era factible que la sociedad española culminara con éxito el proceso transformador que estaba experimentando", su ensayo entraña una nueva - otra más - deconstrucción de la matriz narrativa hegemónica de la Transición, para incorporar, en este caso, el discurso feminista que, según Martínez Pérez, no ha sido suficientemente visibilizado en dicha matriz; pero que, como demuestran las ficciones que rescata del olvido, "fue reflejo y motor de las transformaciones políticas y sociales del periodo".

Sira Hernández Corchete

Centro Universitario de la Defensa (CUD)

Universidad de Zaragoza (UZA)

shernan@unizar.es

Fecha de recepción: 8 de octubre de 2019.

Fecha de aceptación: 2 de diciembre de 2019.

Publicación: 31 de diciembre de 2019

Para citar este artículo: Sira Hernández Corchete, "Peña Ardid, Carmen (ed.), Historia cultural de la Transición. Pensamiento crítico y ficciones en literatura, cine y televisión. Madrid: Los Libros de la Catarata, 2019, 270 págs.”, Historiografías, 18 (julio-diciembre, 2019): pp. 131-135. 